\title{
Deformation-Induced Roughening by Contact Compression in the Presence of Oils with Different Viscosity: Experiment and Numerical Simulation
}

\author{
Grzegorz Starzynski ${ }^{1} \cdot$ Ryszard Buczkowski ${ }^{2} \cdot$ Bartlomiej Zylinski ${ }^{2}$
}

Received: 19 May 2020 / Accepted: 14 October 2020 / Published online: 25 October 2020

(c) The Author(s) 2020

\begin{abstract}
The aim of the work is to show both the similarities and differences in the formation of deformation-induced roughness in contact compression in the presence of oil and the problem of free surface roughing during uniaxial stretching in a plastic area. The relationships between changes in the roughness are caused by the deformation of the sample and the viscosity of oil at the contact area. It has been shown that normal contact loading with the presence of oil initially leads to an increase in surface roughness, then to its smoothening. The results of the experimental research have been compared with numerical simulation made using FSI (Fluid Structure Interaction) and ABAQUS systems. Using finite element calculations, it was possible to explain the phenomenon of roughness formation on the surface of a smooth steel sample. The changes in the structure of the smooth surface resulting from compression in the presence of oil are caused by the rotation and deformation of surface grains. The roughness of this structure is dependent on the viscosity of oil: the more viscous the liquid is, the rougher texture is formed.
\end{abstract}

Keywords Deformation-induced roughening $\cdot$ Viscosity $\cdot$ Finite element method

\section{Introduction}

During deformation, initially smooth metal surfaces are subject to strain induced roughening. Strain induced steel surface roughness is common in many engineering applications. This phenomenon is an undesirable feature that worsens the surface reflectance and the mechanical properties responsible for the location of plastic deformation under load. This change in surface roughness can lead to production problems in particular. It can have a detrimental effect on the surface finish of the sheet, change the coefficient of friction, reduce wear and corrosion resistance. Finally, it can

Ryszard Buczkowski

rbuczkowski@ps.pl

Grzegorz Starzynski

gstarz@ippt.pan.pl

1 Institute of Fundamental Technological Research, Polish Academy of Sciences, Pawinskiego 5B, 02-106 Warsaw, Poland

2 Chair of Structural Mechanics, West Pomeranian University of Technology in Szczecin, Piastow 17, 70-310 Szczecin, Poland lead to undesirable local phenomena which, in turn, may cause damage or the local delamination process of sandwich or coating structures. This is especially the case in the industrial production of food and cans, canisters or sheet metal metallurgy.

For this reason, the deformation-induced roughening process has become the subject of many experimental, theoretical and numerical modeling works. Early research has shown that this process depends on the materials, grain size deformation and surface texture.

Osakada and Oyane [1] were among the first who presented the quantitative and theoretical study of the roughening of free surface during deformation. They showed that surface roughness increases with strain and is affected by grain size and the lattice structure of the metal. Dai and Chiang [2] investigated the plastic deformation-induced surface roughening mechanism of aluminum sheets The average grain rotation and grain size are found to be the dominant contributor to the surface vertical characteristics such as the root-mean-square roughness. The surface horizontal characteristic such as the correlation length is found to be mainly determined by the average grain size. 
Some authors have found deviations from such linearity, which is relevant for larger deformations. Wilson, et al. [3] examining the heterogeneous deformation of copper sheets subjected to biaxial stress, noticed strong surface roughening. The relationship between the Ra parameter describing the roughness profile and the strain was up linear to a certain strain, and above the critical value became strongly nonlinear and grew faster. The dependence of the described curve on the grain size in the copper sheet was also clear: the smaller the grain, the earlier the deviation from linearity occurred.

Generally, the relationship between the parameters describing the average height of asperities (such as $R_{\mathrm{a}}, R_{\mathrm{q}}$ ) can be presented as follows:

$R_{\mathrm{q}}=C \varepsilon d$,

where $\varepsilon$ is the deformation value of the sample, $d$ is the average grain size and $C$ is a constant depending on the material being tested and the determined parameter.

Mahmudi and Mehdizadeh [4] investigating brass sheets under uni- and equi-biaxial stretching showed that, although they obtained linear dependence of roughness parameters on strain and grain size, the slope and location of these curves also depends on the method of sheet metal treatment: fast or slow heating. The increase in roughness is smaller for the fast heating process and the difference increases as the deformation increases.

Wouters et al. [5] examined the relationship between the roughness forming on the surface of samples with $\mathrm{Al}-8.5 \%$ $\mathrm{Mg}$ uniaxially tensioned, and the grain size that varied from 30 to $90 \mu \mathrm{m}$. Their test results revealed a linear dependence of roughness on the strain value and grain size.

Romanova et al. [6] proposed a three-dimensional model of the material with a hardened layer of varying thickness and strength compared to the initial material. A numerical analysis was carried out by the finite difference methods. It was found that internal stresses appearing at the layer boundary and bulk material are responsible for surface roughness which gets larger as the hardened layer gets thinner. It was observed that the local increase in irregularities is due to the movement of connected grains.

Wang and Abe [7] investigated pure aluminum with very large grains. The samples with rain size changes up to $1 \mathrm{~mm}$, corresponding to $1 / 2,1 / 4$, and $1 / 3$ of sample thickness, were tensioned. The $R_{\mathrm{a}}$ relationship also increases linearly for all the samples with an increase of deformation applied. In this work an expanded version of Eq. (1) has been proposed:

$R_{\mathrm{a}}=C \varepsilon d^{n}$.

It is thought that when $n=1$, the surface roughness caused by non-uniform deformation is completely dependent on grain size. At the same time, if $n=0$, the value of roughness is caused by factors independent of grain size. The value of $n$ can be determined from the relationship between the rate of change of surface roughness $R_{\mathrm{a}} / \varepsilon$ and the average grain size $\mathrm{d}$ in the double logarithmic scale. The slope of a straight line obtained from the fitting by the least squares method allows us to determine the value of $n$ in Eq. (2). For the test samples in the calculated value of $n=0.88$, which means that only a small part of the roughness is caused by factors independent of particle size, such as, for example, slip bands.

Song et al. [8] conducted a plastic deformation measurement using a confocal laser scanning microscope of aluminum sheets deformed uniaxially. They showed that the roughness of sheets after deformation is primarily affected by grain rotation, which is greater in the surface layer than inside the material, as well as by locally heterogeneous grain deformation. Thanks to the measuring technique used, it was possible to study the relationship between the deformation of individual grains and the roughness curve resulting from this deformation.

Zhou and Su [9] investigated the surface topography of aluminum and titanium alloys after plastic deformation in the longitudinal and transverse directions using white-light interferometry and a fractal method of analysis. Initially, the homogeneous geometric surface structure changed in different ways depending on the measurement direction in relation to the deformation direction, creating a new, anisotropic structure. This structure was different for aluminum and titanium. Fractal analysis showed that length correlation is in the same order as the size of the grains, but it varies depending on the direction of measurement and the tested material. The standard 3D roughness parameter $\left(S_{q}\right)$ measured for the tested surface grew linearly with the given deformation.

Shia et al. [10] presented a numerical simulation of surface roughness during the tube blow forming process. Simulation data were available from the measurement of electronic backscatter diffraction (EBSD). The roughness of formed aluminum bottle is linked to the difference between the orientation of the neighboring grains, and to the initial texture. The roughness of the formed aluminum bottle is associated with the difference between the orientation of adjacent grains and also with the initial texture.

Cai et al. [11] present an interesting approach (the trapezoidal tensile aluminum alloy sample) to obtaining a continuous strain distribution on the sample after one deformation. Using a specially designed stage, it was possible to measure changes in surface roughness using an electron scanning microscope (SEM) in situ for increasing tensile load. The surface microstructure was also determined using the EBSD. The results presented differed from those generally accepted: the dependence of Ra on deformation increased non-linearly to $7 \%$ level, then slightly decreased. From the SEM results it was concluded 
that the appearance of roughness was caused by a heterogeneous deformation between and within the grains. The increased number of slip bands launched has resulted in uniform deformation and a slight reduction in roughness above the critical value.

Romanova and her team have carried out a series of works on titanium research in recent years (2016-2020) [12-15]. This articles addresses the problem of multiscale surface roughening in titanium subjected to uniaxial tension. Based on the experimental data obtained, 3D polycrystalline models with explicit consideration of grain structure were generated and implemented in finite element calculations. The experimental and numerical results obtained have shown that a series of multiscale surface undulations are formed on the free surface of the specimen subjected to tension. Larger displacements are associated with relative grain motion. The main conclusion drawn from the experimental and numerical results is that it is the mesoscale that will furnish a clue to prediction of plastic strain localization and fracture of materials far in advance of the macroscale manifestation of these processes [12]. The influence of a texture on the mesoscale deformation-induced surface roughening in titanium polycrystals was studied using direct microstructure-based simulations [13]. The grain constitutive behavior was described in terms of crystal plasticity, with the grain orientations being assigned randomly or representing a basal texture. The mesoscale roughness parameter was shown to grow nonlinearly with the plastic strain of the evaluated mesoscale regions. The basal texture was shown to significantly affect the plastic strain localization and roughness patterns. In [14, 15] the three-dimensional numerical analysis was performed of the deformation-induced roughening in polycrystalline specimens with and without surface-hardened layers. Threedimensional microstructure-based constitutive models are developed, using crystal plasticity, and employed in finite element calculations of uniaxial tension. Grain structure is shown to be responsible for free surface roughening under uniaxial loading. The surface-hardened layer moves the grain structure away from the free surface, smoothing out the microscale folds formed due to displacements of individual grains, while the mesoscale surface undulations remain clearly visible. This study allowed distinguishing between the grain size and texture effects.

Kucharski and Starzynski [16] in their earlier paper present an experimental study of the opposite problem: initially rough surfaces have been compressed by smooth flat counter sample in the presence of lubricant and in dry state. The results of widely analyzed 3D changes in roughness parameters as a function of sample deformation are presented. The trend to the asymptotic state was noted for the lubrication case and its absence for the dry sample. The observed stabilized state was explained by the hydrostatic reaction of the lubricant.
The opposite problem will be presented and analyzed herein - the creation and evolution of a new structure of smooth surface during contact compression. Available literature provides the results of research on surface roughening due to plastic deformation of materials that relate primarily to tensile samples with a free surface. In this work we investigate the roughening of a surface subjected to contact compression in the presence of oil film. The relationships between changes in the roughness are caused not only by the deformation of the sample, but also by the viscosity of oil in the contact area. It has been shown that normal contact loading with the participation of oil initially leads to an increase in surface roughness, then the surface gets smoother.

Available literature provides the results of research on surface roughening due to plastic deformation of materials that relate primarily to tensile samples with a free surface. What has not been analyzed so far the FSI (fluid-structure interaction) analysis considered an oil layer on the steel surface of the sample. The analysis requires the preparation of two separate models: for a solid and a liquid and marking the friction contact surfaces between which the interaction will take place. FSI (fluid-structure interaction) analysis allowed for the oil layer on the steel surface of the sample to be taken into account. Finite element calculations were performed taking into account physical non-linearities (plasticity) and geometric non-linearities (large strains). The changes in the structure of the smooth surface resulting from compression in the presence of oil are caused by the rotation and deformation of surface grains. The roughness of this structure is dependent on the viscosity of oil: the more viscous the liquid is, the rougher texture is formed. Moreover, the developed experiment allowed to show the influence of the oil film viscosity on the formation of roughness and to find the critical point of deformation, above which the surface structure begins to flatten.

\section{Experimental Procedure}

For the experiment, two steels have been chosen: H18N9 austenitic stainless steel and S235 steel with characteristic strength shown in Fig. 1. The yield strengths of these steels are very similar (approx. $300 \mathrm{MPa}$ ), while the further characteristic varies considerably. Austenitic steel monotonically strengthens, while S235 steel, after an area of instability in the early plasticity, strengthens slightly and above the strain 0.15 begins to weaken and crack before the deformation of 0.30 .

Because, as shown in the introduction, deformationinduced roughness depends, among others, on the grain size, the samples were chosen so that the size of grains in the both steels were as close as possible (Fig. 2). The average grains size are $30-40 \mu \mathrm{m}$. 


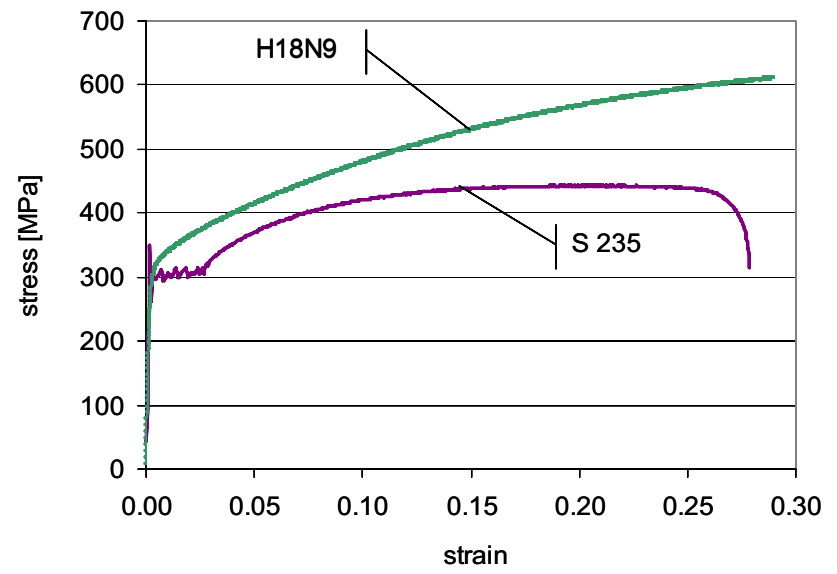

Fig. 1 Strength curves of H18N9 and S235 steels

Initially, flat discs (approx. $50 \mathrm{~mm}$ in diameter) were cut out from the tested steels, then subjected to grinding and fine polishing. As a result of such treatment, almost a mirror surface was obtained, having a roughness $S_{\mathrm{a}}$ of the order of several nanometers. The circle samples ( $8 \mathrm{~mm}$ diameter) were then cut out from the discs so that highly reproducible surfaces of individual samples have been obtained. To study the effect of oil viscosity on the condition of surface subjected to contact compression, we selected two oils, for which the dependence of viscosity on temperature was well examined by the oil company (see Table 1 ).

The experiment was carried out on circular samples with a thickness of approx. $3 \mathrm{~mm}$ and a diameter of $8 \mathrm{~mm}$, which were compressed in the modernized test apparatus for normal contact. Kucharski and Starzynski [17] described the experimental set in details. Operation of the device is based on a hydraulic press that is capable of producing large normal forces. The samples were placed between very smooth, flat plates of a very hard material (WC-tungsten carbide).
Table 1 Viscosity [in $\mathrm{mm}^{2} / \mathrm{s}$ ] of water and oils (data by LOTOS oil company)

\begin{tabular}{lllll}
\hline Fluids & \multicolumn{4}{l}{ Temperature } \\
\cline { 2 - 5 } & $40^{\circ} \mathrm{C}$ & $25^{\circ} \mathrm{C}$ & $20^{\circ} \mathrm{C}$ & $15^{\circ} \mathrm{C}$ \\
\hline Water & 0.65 & 0.9 & 1.0 & 1.15 \\
OIL-L-AN 22 & 22.7 & 42 & 55 & 70 \\
Oil-Transmil SP 680 & 660.7 & 2250 & 3250 & 5500 \\
\hline
\end{tabular}

Oil was placed between the surface of the sample and the WC plate, so the sample was loaded through the thin oil film formed on the surface of the sample and the WC plate (Fig. 3).

The compressive tests have been executed in the presence of two oils having very different viscosity-AN 22 and SP 680 (see Table 1). The load was applied in two ways: (i) direct load to a predetermined force- the following samples showed relative deformation $0.033,0.087,0.197,0.333$. In comparative diagrams there is no additional load description in the legend, (ii) the loading up to predetermined forces was performed on one sample, in seven steps, and the following deformations were obtained: $0.0330 \rightarrow 0.087 \rightarrow 0.157 \rightarrow 0$. $197 \rightarrow 0.267 \rightarrow 0.333 \rightarrow 0.37$. After successive deformation, the sample was removed from the device, washed and measured with a profilometer, then again the next step of loading was applied. In the legend of the comparative diagrams this method of loading is described as "steps".

\section{Results and Discussion}

It can be stated in general that as a result of mutual contact loading of the smooth polished surfaces with different oil films between them a new geometric structure is created on the surface. This structure is completely different from the
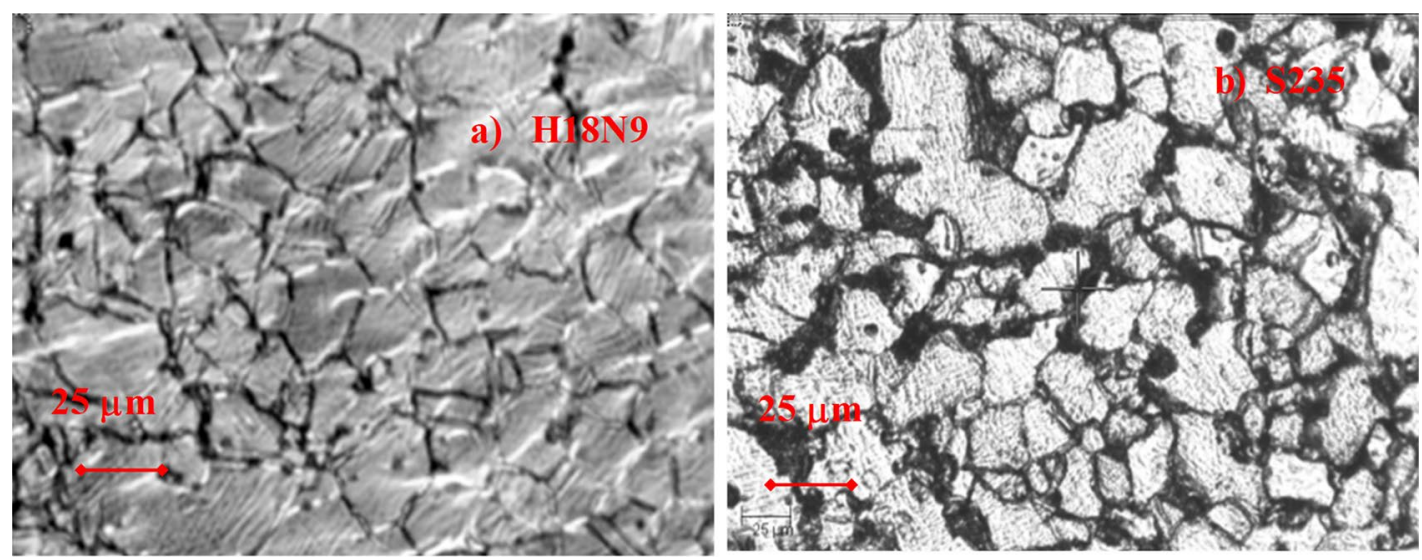

Fig. 2 The micrographs of the surface for both steel: a H18N9 and b S235 


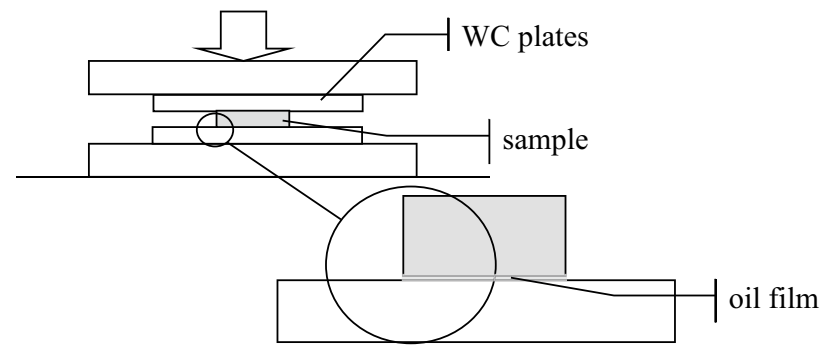

Fig. 3 The diagram of the contact loading of the sample with the presence of oil film

structure before loading and varies for highly viscous oil (SP 680) and an oil of low viscosity (AN 22). To characterize this structure, two parameters have been compared: the amplitude $S_{\mathrm{a}}$ (arithmetic mean deviation of the surface from the mean plane) and the horizontal $P_{\mathrm{sm}}$ (average distance of the asperities in the profile, which may be called the profile wavelength. Parameter $P_{\mathrm{sm}}$ was referred to the profiles, because there is no equivalent parameter for the surface. As the parameter varied a lot from profile to profile, the value shown in the diagrams is the average of all (100) of the measured profiles of the examined surface. A comparison of the peak height distributions of new surface structures is also made.

\subsection{Visualization of Changes in Surface Structure (Roughening)}

The diagrams below illustrate the results of the experiment. Figure 4 represent 3D views of the surfaces before loading (Fig. 4a) and the deformation-induced surfaces after loading (Figs. $4 \mathrm{~b}, \mathrm{c}$ ) for austenitic steel. To better illustrate the changes that occur during compression of the surface with various oils, visualization is shown in the same scale. It can be seen that the surfaces are substantially different. Loading with highly viscous oil generates occasional large asperities, while loaded with low viscosity oil the surface gets heavily roughened by asperities of small height. It should be noted, as confirmed in the next diagrams comparing parameters of the surface, that maximum asperity amplitudes in generated surfaces are several times higher than roughness amplitudes before loading. The last of these diagrams (Fig. 4d) shows a 3D view of the S235 steel surface after loading, which are
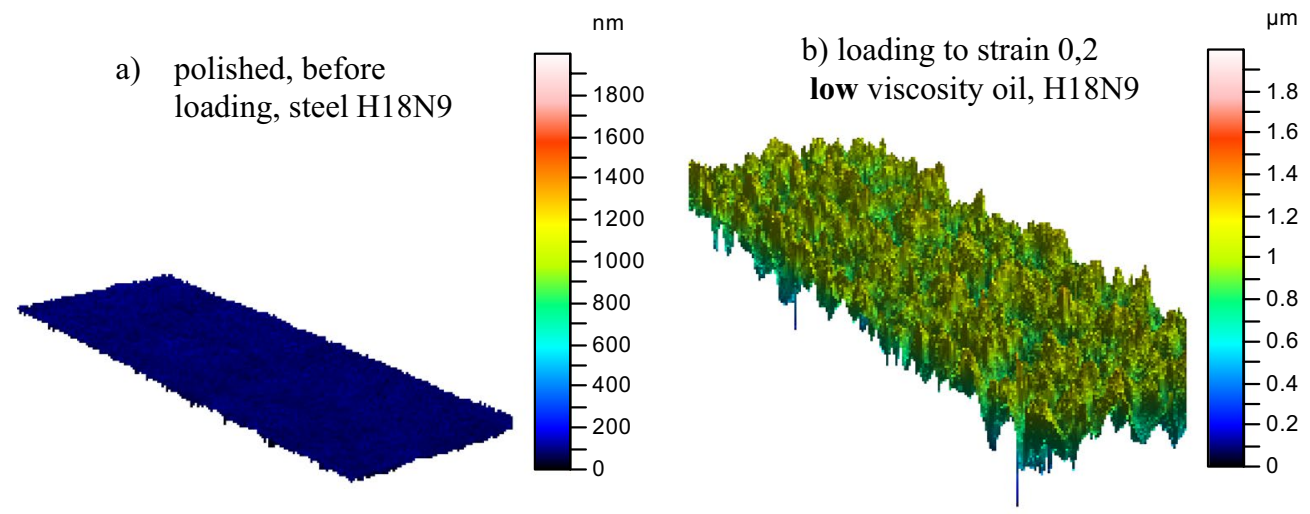

b) loading to strain 0,2

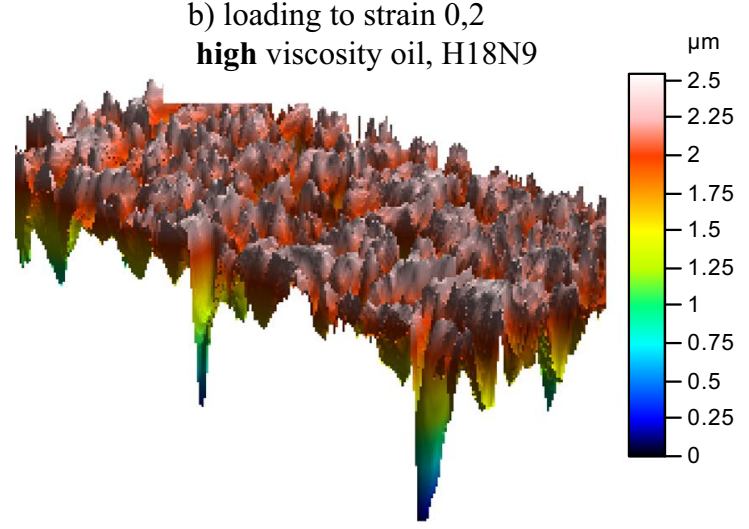

b) loading to strain 0,2

high viscosity oil, S235

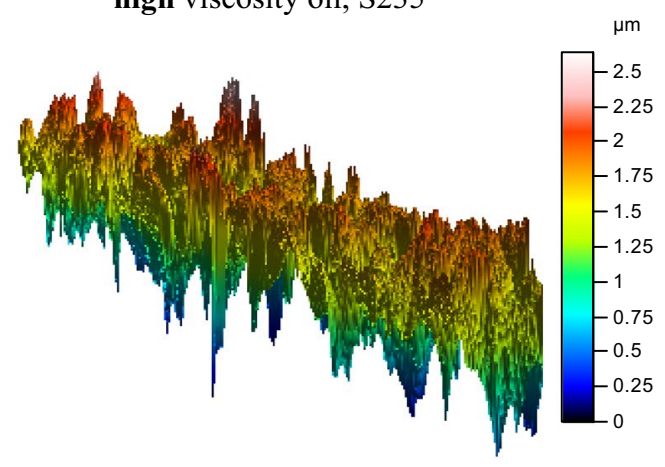

Fig. 4 3D view of steel H18N9 surface: a polished, before loading, b after loading to strain 0.2 with low viscosity oil AN 22 , $\mathbf{c}$ after loading to strain 0.2 with high viscosity oil SP $680, \mathbf{d}$ after loading to strain 0.2 with high viscosity oil SP 680 (steel S235) 
even higher than for a similar case of austenitic steel (note that the scale of $\mathrm{z}$ ordinate at Fig. $4 \mathrm{~d}$ is twice larger).

\subsection{Comparison of Height Parameters of the New Structures}

The figures below show quantitative changes in the new geometric structure of the surfaces for the two types of steel and the two oils, generated after the compression.

Figures 5 and 6 compare the amplitude parameter $S_{\text {a }}$ (describing the average height of irregularities) as a function of the total deformation of the samples in the presence of both oils, for austenitic steel (Fig. 5, in the description always denoted by the letter $\mathrm{H}$ ) and ordinary S235 steel (Fig. 6, in the description always denoted by the letter S). There are large differences in the values of the parameter $S_{\mathrm{a}}$ for the new surface obtained after loading with different oils. The maximum $S_{\mathrm{a}}$ value for high viscosity oil SP680 reaches almost $0.3 \mu \mathrm{m}$ for austenitic steel and $0.5 \mu \mathrm{m}$ for ordinary S235 steel. For low viscosity oil this parameter does not exceed $0.07 \mu \mathrm{m}$ for austenitic steel and 0.18 for ordinary S235 steel. It should be born in mind that the surface roughness before loading was $S_{\mathrm{a}}=0.013 \mu \mathrm{m}$.

During the loading with high viscosity oil, the influence of the load history on the amplitude of asperities is significant, while with low viscosity oil the influence is very small. For the high viscosity oil there is a clear maximum of asperity height on the curve $S_{\mathrm{a}}$ as a function of deformation for the newly created surface. It can be stated that in the initial phase, as a result of compression and oil presence, a new surface is built and as the load increases the amplitude of the asperities grows, reaching a certain maximum. Further loading will decrease the extent of roughness, consisting in

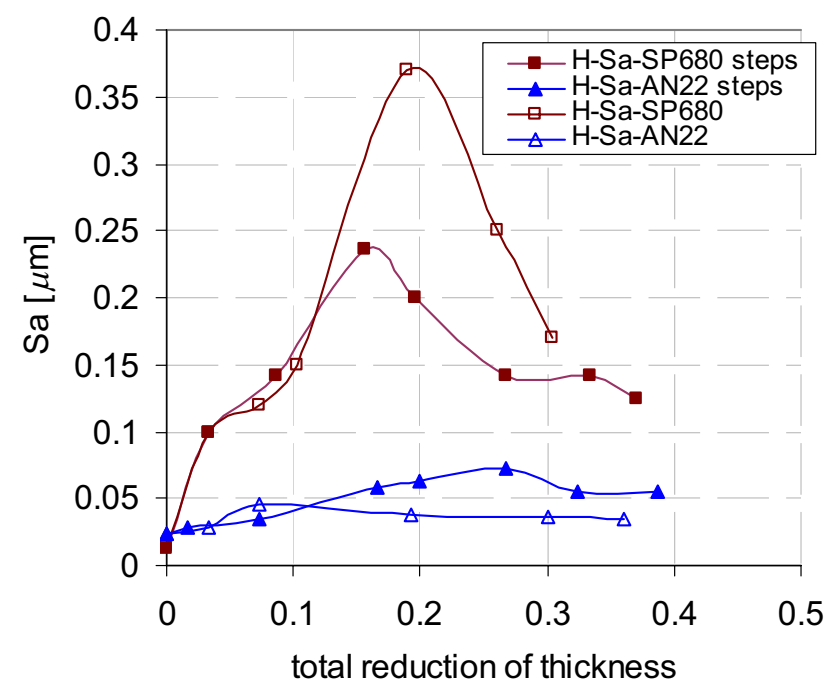

Fig. 5 Comparison of $S_{\mathrm{a}}$ value for H18N9 steel, with two different oils, loaded by different kind of compression (direct and by steps)

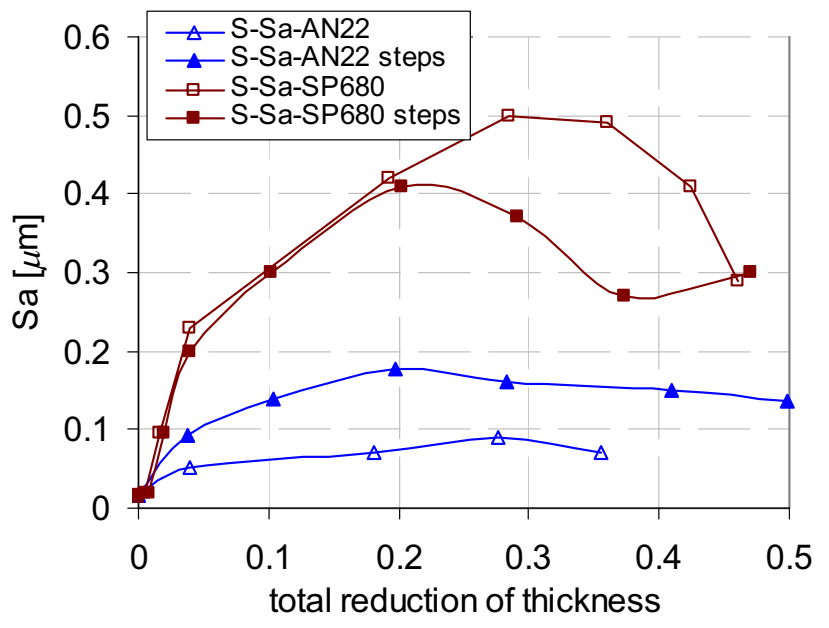

Fig. 6 Comparison of $S_{\text {a }}$ value for S235 steel, with two oils, loaded by different kind of compression (direct and by steps)

the crushing of previously constituted structures. The same process-decreasing of the of roughness-is observed for the contact compression of the surface earlier produced by a variety of technologies such as sand blasting, EDM or other. It appears that beyond a certain load, the condition is stabilized at the level $S_{\mathrm{a}}$ approx. $0.12 \mu \mathrm{m}$, for austenitic steels and, in any event, the reduction becomes very slow. For ordinary S235 steel this could not be seen, because for the deformation 0.3 only the force to deformation relation ceased to be monotonic and the material was crucially weakened, as shown in the Fig. 1.

The location and size of maximum asperities depends on both the history of loading and on the material sample. For both steels and the higher viscosity oil (SP680) it can be compared graphically (Fig. 7). The greatest maximum occurs on the curve describing direct loading for S235 steel and occurs at total strain 0.3. For austenitic steels the maximum is smaller and occurs for deformation 0.2. The curves, representing loading carried out in seven steps, show certain maxima, but slightly smaller, localized earlier, and for a smaller strain value. The nature of this relationship is maintained for both steels. It is worth noting that up to a certain deformation ( 0.15 for austenitic steel and 0.2 for S235 steel) the shape of the examined curve is independent of the loading history. This is more clearly visible in the next figure illustrating the relationship of the parameter values as functions of the stress in the specimen (Fig. 8).

Additional tests were also performed on specimens made of both steels for small loads. The specimens were loaded to 100, 200 and $300 \mathrm{MPa}$ in an Instron-made testing machine capable of setting accurately the relatively small compressive forces. The test confirmed that the surface will not deform until the yield point is exceeded. This can be seen in Fig. 8, which shows graphs as a function of true stress 


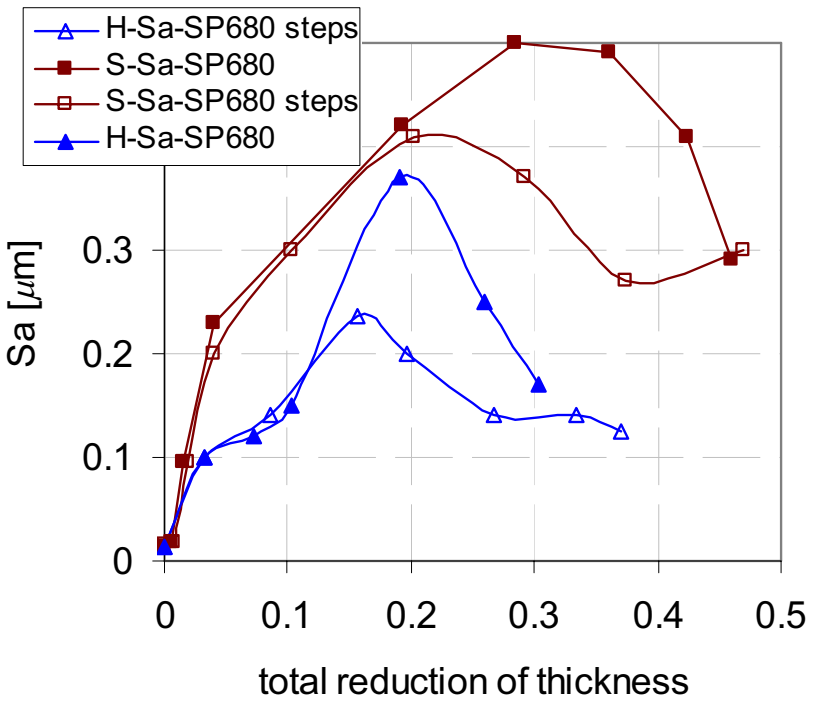

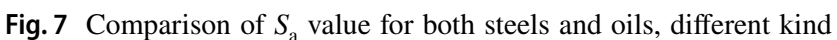
of compression (direct and by steps) as a function of total deformation of the specimen

of the sample with high viscosity oil. Exceeding the yield limit results in a very strong initial growth roughness, significantly earlier for S235 steel, which is associated with lower yield strength of the steel. The similar process occurs with oil of low viscosity, but is much weaker. Maxima in principle do not occur, and if they do, within the error limits. A new structure is created, but it quite quickly stabilizes at the level $S_{\mathrm{a}}$ approx. $0.05-0.15 \mu \mathrm{m}$.

The changes are indeed very large and dependent on oil viscosity as well as tested material. The roughness created on the surface of S235 carbon steel has greater amplitude than on austenitic steel. Two loading histories have been compared: direct loading to predetermined force and step by step loading where the surface was measured profilometrically after each step.

In Fig. 8, three phases of surface deformation can be clearly seen to change its structure:

Phase 1 - elastic, below the yield point $(<300 \mathrm{MPa})$-no change in surface roughness,

Phase 2-plastic, the new structure of surface resulting from rotation and deformation of surface grains is generated up to the critical point. Critical points are between 20 and $30 \%$ of the total deformation of the sample and depend on the loading history and sample material.

Phase 3-plastic, beyond certain critical point the roughness is reduced, because the surface is crushed by a countersample.

\subsection{Comparison of Horizontal Parameters of New Structures}

The previous chapter presents changes to the standard parameter $S_{\mathrm{a}}$, describing the value of the roughness amplitude. For a comprehensive description of deformationinduced surface structure, it is important to show changes the parameter that determines horizontal structure. The parameter describing these changes is $P_{\mathrm{Sm}}$. This parameter is expressed in the length unit of the $Z$ axis, in this paper, in $\mu \mathrm{m}$.

$P_{\mathrm{Sm}}=\frac{1}{m} \sum_{0}^{m} P_{\mathrm{Si}}$

The horizontal parameter $P_{\mathrm{Sm}}$ (average distance between the asperities in the profile, which may be called wavelength of the profile) for both steels and oils is independently compared in Figs. 9 and 10. Figure 9 shows the results versus
Fig. 8 Comparison of $S_{\text {a }}$ value for both steels and oils, different kind of compression (direct and by steps) as a function of stress

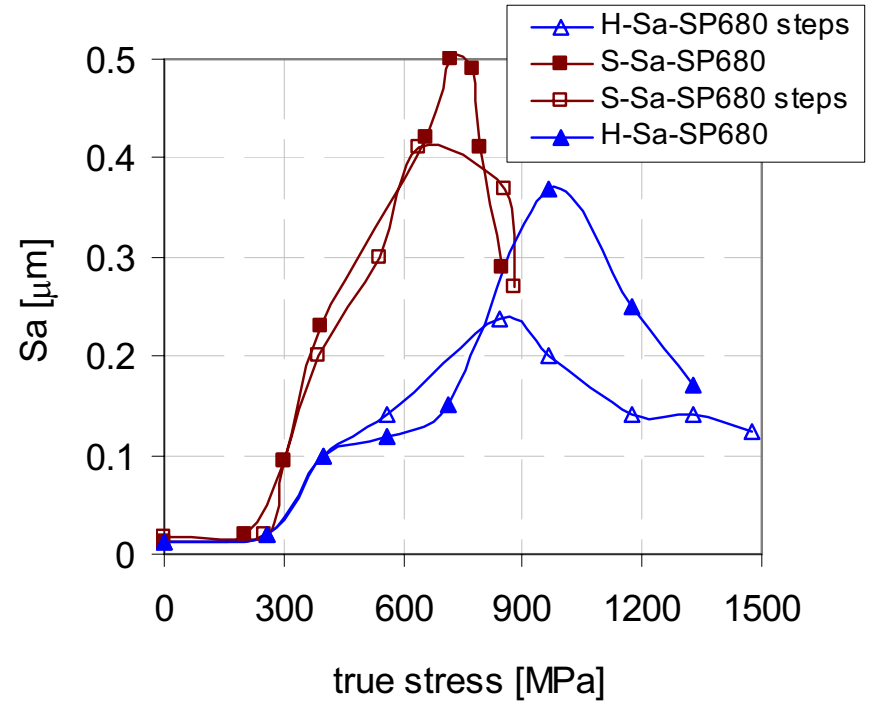




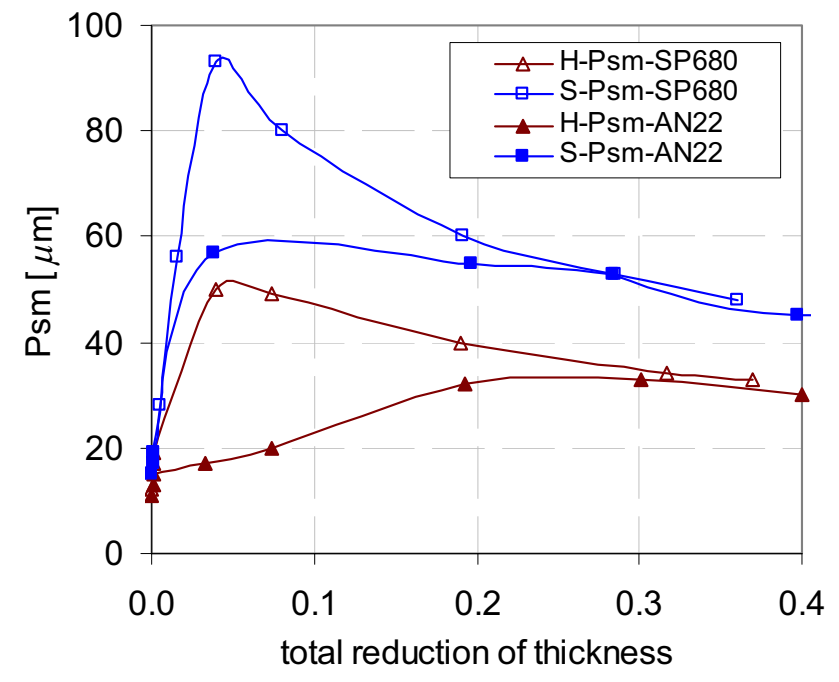

Fig. 9 Comparison of parameter $P_{\mathrm{Sm}}$ versus reduction of thickness for both steels and oils

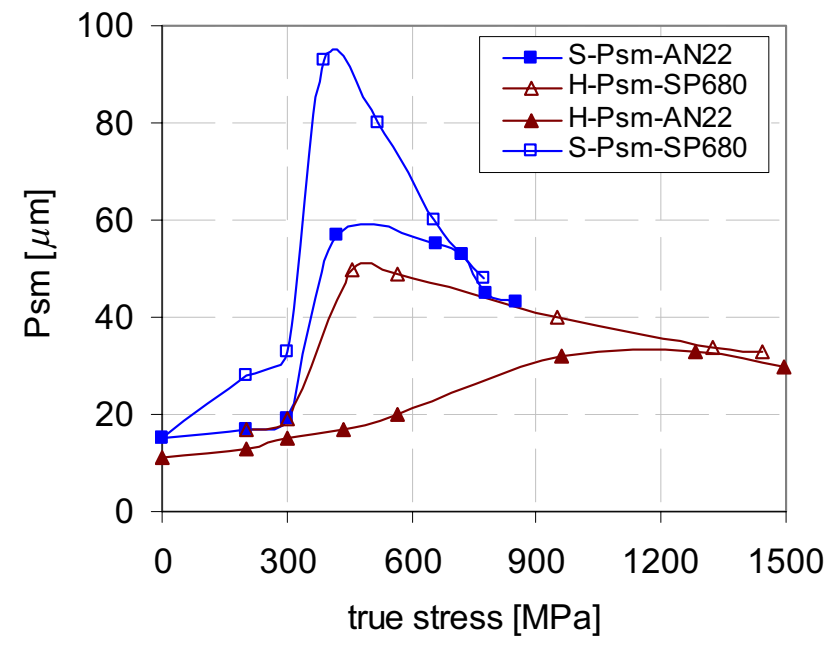

Fig. 10 Comparison of parameter $P_{\mathrm{Sm}}$ versus true stress for both steels and oils

total reduction of thickness, Fig. 10 as a function of true stress.

For high viscosity oil and austenitic stainless steel $(\mathrm{H})$ parameter $P_{\mathrm{Sm}}$ during loading grows rapidly and achieves a maximum (about $50 \mu \mathrm{m}$ ) that due to further load slowly descends (Fig. 9). This relationship is similar for S235 steel, but the maximum is almost twice as large $(90 \mu \mathrm{m})$ and there a slow decline in the value and stabilizes at a level of approx. $45 \mu \mathrm{m}$. It is interesting that the history of loading has practically no influence on the course of the changes described. With large deformations (above 0.3), the difference between roughness for different oils disappears (Figs. 9, 10). It is related to the dominance of flattening by the compression previously built asperities. Further deformation causes the structure to stabilize at $30 \mu \mathrm{m}$ for H18N9 austenitic steel and $45 \mu \mathrm{m}$ for $\mathrm{S} 235$ carbon steel.

\subsection{Comparison of Peak Height Distributions of New Structures}

The existence of three phases of creating the surface structure of a smooth sample subjected to compression with oil is confirmed by changes in the height distribution of asperities as a function of compression load for the steels and oils tested.

Figures 11, 12, 13, and 14 show the density of the peak height distribution in the surface structure before and after subsequent loads for further deformation for both steels with the presence of high viscosity oil SP680. An analysis of these diagrams confirms some earlier conclusions drawn from the comparison of the changes of height parameters.

The peak height distribution of the polished surface before deformation is symmetrical and close to the Gaussian distribution, especially for austenitic steel H18N9 (Fig. 11a). On the axis $x$ there is the range of roughness (difference between height of maximal peak and depth of minimal valley) obtained from the experimental test. To compare the effective range of the distribution of asperities, we "cut" the highest and lowest asperities at the level of $0.3 \%$ of the bearing ratio curve. The idea is to measurements of single high peaks or deeper valleys do not distort the comparison of the global results. The value of this range differ from $160 \mathrm{~nm}$ for undeformed surface (Fig. 11a) to $2.2 \mu \mathrm{m}$ for maximal deformed sample (Fig. 11c). It can be seen that the distribution center for undeformed surface is located at a level of approx. $115 \mathrm{~nm}$ and the effective range is $\pm 45 \mathrm{~nm}$. Even a slight deformation (0.04) causes a large change in the distribution (Fig. 11b). The distribution is no longer symmetrical the maximum shifts to approx. $1.1 \mu \mathrm{m}$, with $300 \mathrm{~nm}$ effective range in the peaks and $550 \mathrm{~nm}$ in the valleys. This means that surface roughening occurs.

The subsequent strains makes the height distribution asymmetric, which indicates the initial deformation of asperities. The maximum remains at a level similar to that previously described, but the effective range of peaks does not exceed $150 \mathrm{~nm}$, increasing in the valleys to $600 \mathrm{~nm}$. Another strain retains this asymmetric trend (Fig. 11c).

Figure 12 presents an overview of the results described above, offering a better comparison of the changes taking place in the emerging roughness as a function of increasing surface deformation. Two trends are clearly visible. In the initial phase, the deformation creates a new structure characterized by shifting the location of the maximum toward higher values. After a critical point (approx. 0.2 strain), the trend is reversed and the location of the maximum shifts towards the smaller surface roughness. This indicates the strong deformation of peak tops. 

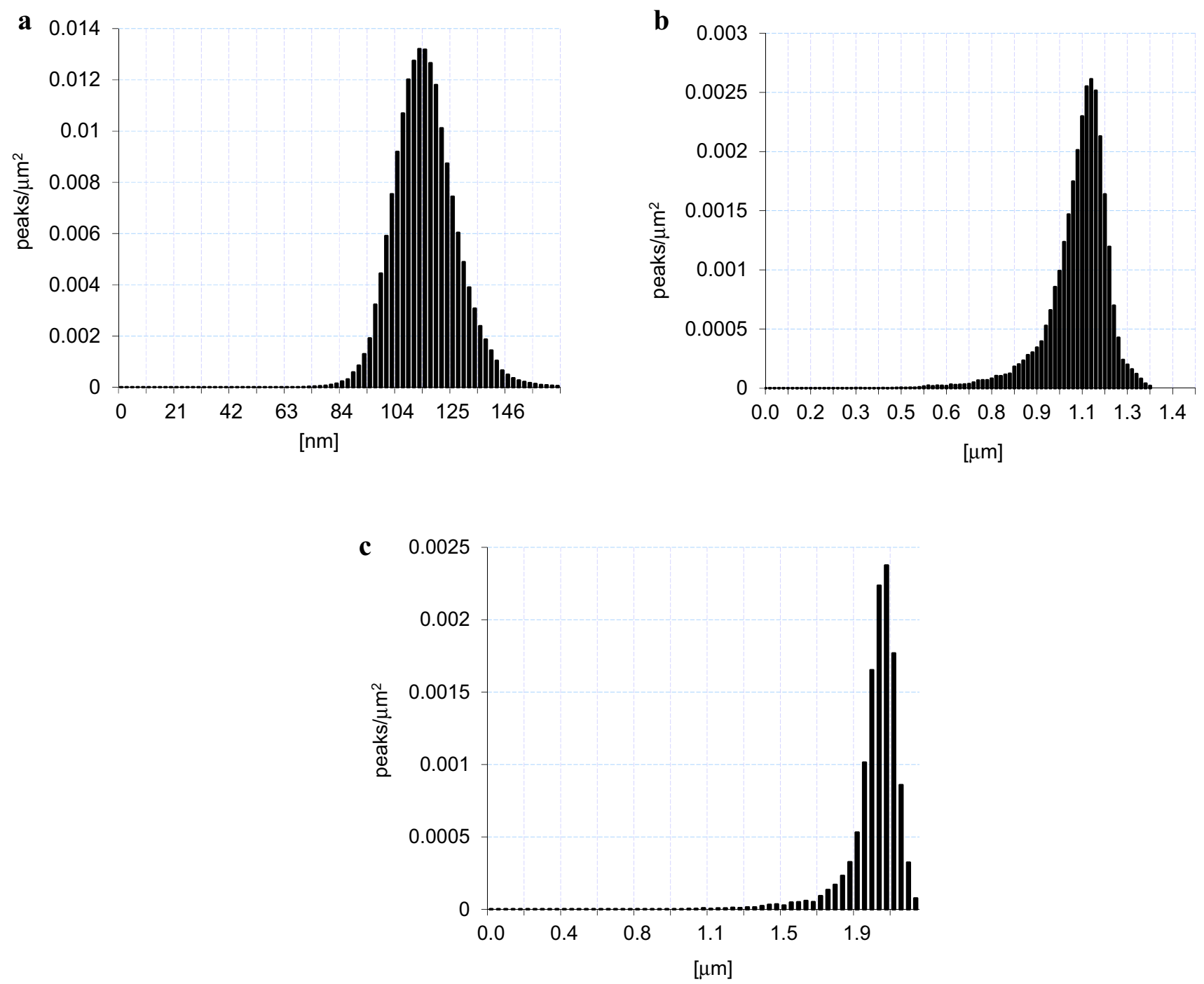

Fig. 11 a Peak height distributions for H18N9 steel before contact compression. b Peak height distributions for H18N9 steel after contact compression (strain 0.04). $\mathbf{c}$ Peak height distributions for H18N9 steel after contact compression (strain 0.27)

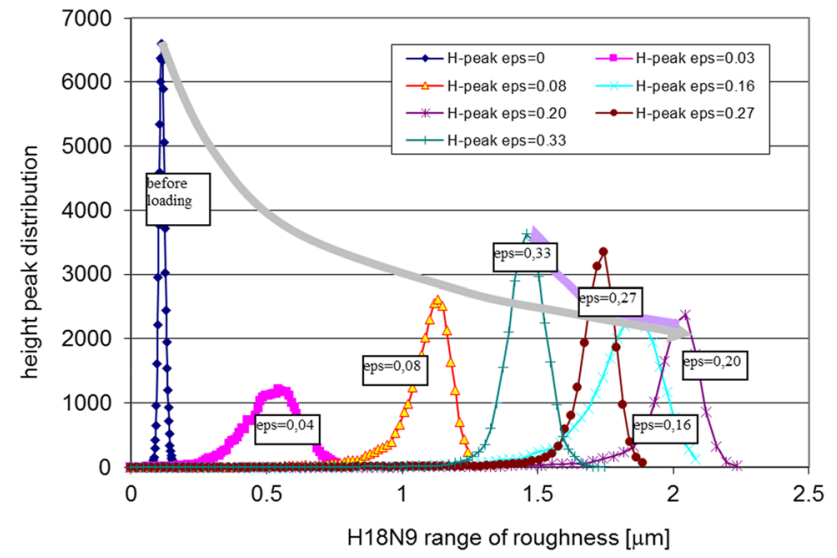

Fig. 12 Summary of results of density peaks height distribution as the function of roughness range for the austenitic steel H18N9
The surface structure which formed on S235 steel (Fig. 13a-c) is generally similar to the one described previously - before deformation the distribution is roughly symmetric and the location of the maximum is similar (the center is located at a level of approx. $130 \mathrm{~nm}$, with the effective range $\pm 40 \mathrm{~nm}$. After deformation of 0.1 the effective range significantly increased (to nearly $\pm 0.7 \mu \mathrm{m}$ ), which is maintained during the further deformation of the sample. The maximum strain (up to 0.36) indicates strong deformation of the peak tops.

The above summary of the results (Fig. 14) shows two trends, like for austenitic stainless steel. In the initial deformation the peak is shifted towards higher values. After passing a critical point the trend reverses and the location of the maximum shifts towards lower values of the roughness. The differences, in comparison to Fig. 12, 

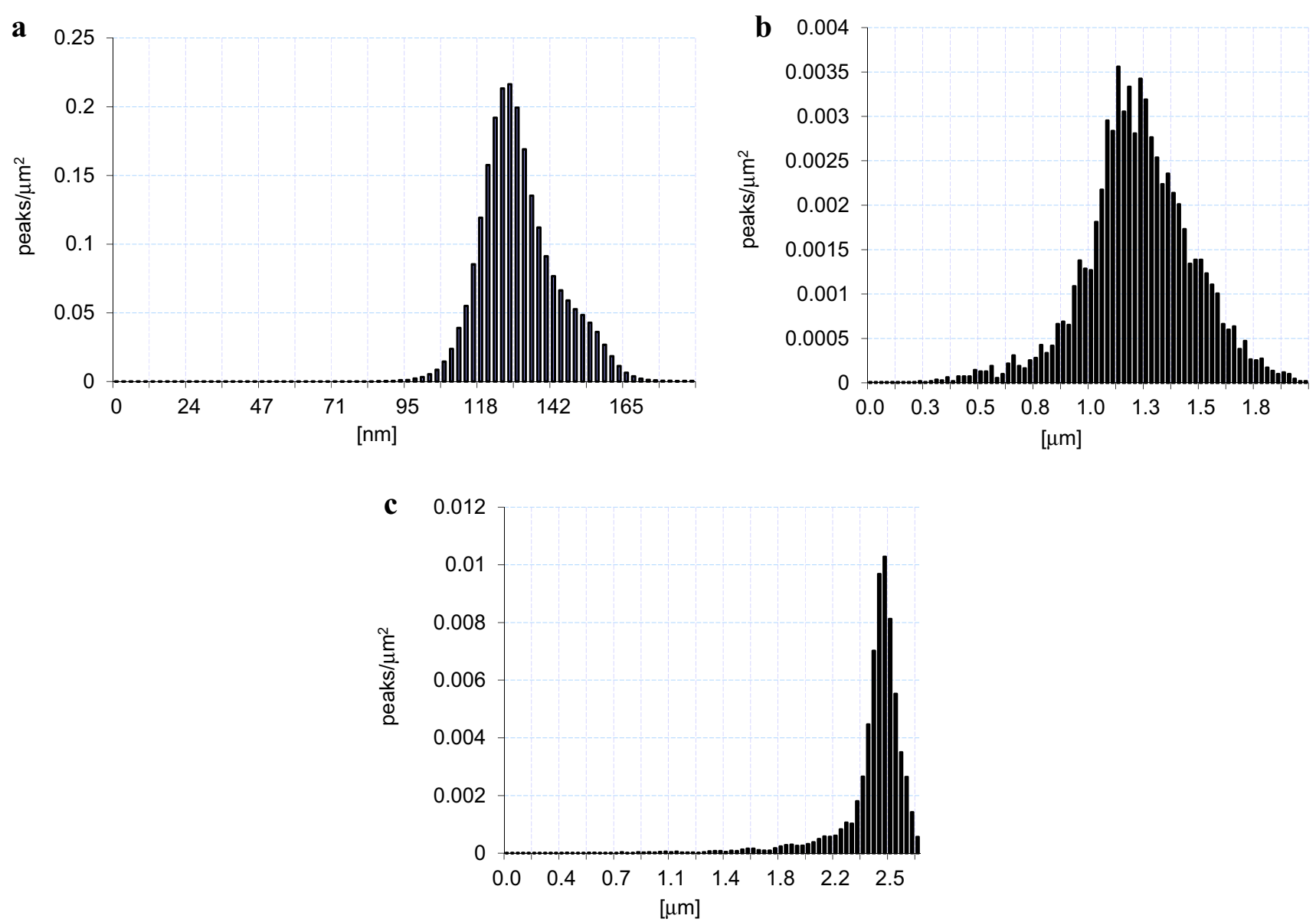

Fig. 13 a Peak height distributions for S235 steel before contact compression. b Peak height distributions for S235 steel after contact compression (strain 0.1). c Peak height distributions for S235 steel after contact compression (strain 0.36)

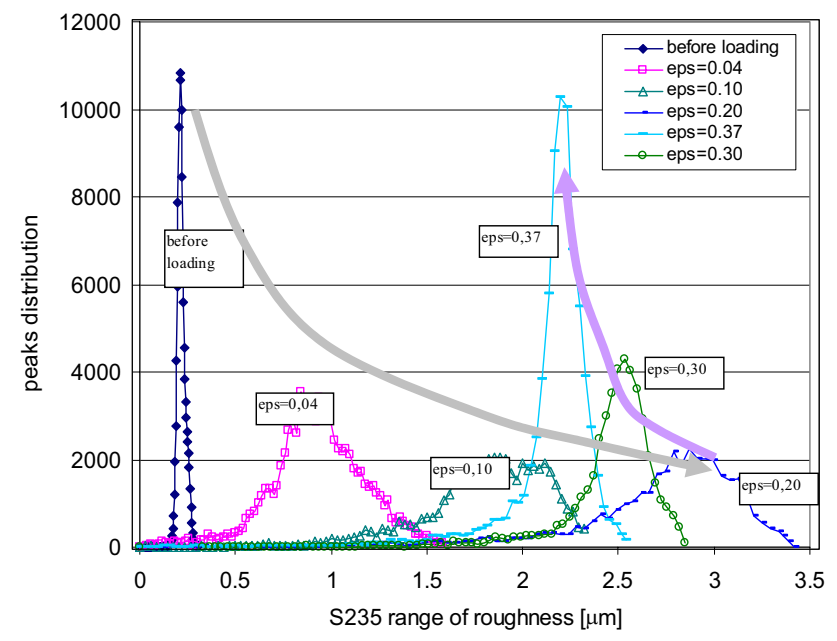

Fig. 14 Summary of density peaks height distribution as the range of roughness function for $\mathrm{S} 235$ steel are only in the values of the location and size distribution curves.

\subsection{Numerical Simulation and Calculations of Surface Roughness}

In order to model and determine changes in roughness of the initially smooth surface subjected to stamp loading, analogous to the experiment, FSI (Fluid Structure Interaction) numerical analyzes were performed using the ABAQUS system (ver. 6-14). FSI (fluid-structure interaction) analysis allowed taking into account the oil layer on the steel surface of the sample. FSI analysis in ABAQUS is possible only for spatial dynamics problems with integration over time explicit or implicit method. The analysis requires the preparation of two separate models: for a solid and a liquid, and marking the surfaces between which the interaction will take place.

The calculations were carried out for a steel sample (dimensions: diameter $8 \mathrm{~mm}$, thickness $3 \mathrm{~mm}$ ) taking into account the oil layer (high viscosity) between the punch 
and the upper surface of the sample as in the experiment. The fluid layer was $0.093 \mathrm{~mm}$. The steel sample model took into account the granular structure of the material, modeling grains (irregular shapes and dimensions in the range of 30-40 $\mu \mathrm{m}$ ) in the layer at the upper surface of the sample (Fig. 15a, b) taking into account the contact between sample and oil layer. The thickness of the layer consisting of grains was about $0.07 \mathrm{~mm}$. Friction contact was defined between the grains and the steel sample. It is assumed friction coefficient between grains and steel sample equals to 0.3 . Due to the axially symmetrical nature issues were prepared sector clipping equals one degree of the full spatial model consists the sample and the oil layer (Fig. 15c). Boundary conditions (for the steel sample and the oil layer) were set in a cylindrical system $(r, t, z)$. Displacements in the tangential direction $(t)$ are blocked on the both side walls. The vertical displacements $(z)$ are blocked on the bottom panel.

For the presented model, dynamic analysis (implicit type with explicit integration scheme) was carried out in the time range from $t=0$ to $t=1 \mathrm{~s}$. During this time, load was applied, gradually increasing the pressure in the fluid from zero (time $t=0 \mathrm{~s}$ ) to maximum $600 \mathrm{MPa}$ (time $t=1 \mathrm{~s})$. The complete FSI model together with the mesh of spatial finite elements is shown in Fig. 16. The steel sample model uses C3D10 finite elements. The fluid (oil) was modeled with FC3D8 type elements (nomenclature according to ABAQUS system). The number of finite elements per grain varied from a few to several.
The FEM calculations were performed taking into account physical non-linearities (plasticity) and geometric non-linearities (large deformations). The following plasticization characteristic is assumed:

\begin{tabular}{lll}
\hline & $\begin{array}{l}\text { Yield stress } \\
(\mathrm{MPa})\end{array}$ & Plastic strain \\
\hline 1 & 235 & 0 \\
2 & 300 & 0.03 \\
3 & 350 & 0.05 \\
4 & 400 & 0.1 \\
5 & 420 & 0.23 \\
\hline
\end{tabular}

For the steel sample (both the material between the grains and the grains), the following material constants were adopted: density $7850 \mathrm{~kg} / \mathrm{m}^{3}$, Young's modulus $E=210,000 \mathrm{MPa}$ and Poisson's ratio $v=0.3$. For the oil layer it was assumed: density $1000 \mathrm{~kg} / \mathrm{m}^{3}$ and dynamic viscosity $0.0005 \mathrm{~Pa}$ s.

As a result of increasing the load, the distances between the grains change as shown in Fig. 17a-d (the relative distances between the marked points, in red). The changes of the relative distances between grains versus normal contact loading is illustrated in Fig. 18.

The initial (undeformed) and final (deformed) steel sample model is shown in Fig. 19. The upper surface of the sample, initially flat, finally becomes rough. This can be explained by grain deformation and rotation as shown in Fig. 19. On the left side of the figure there are large

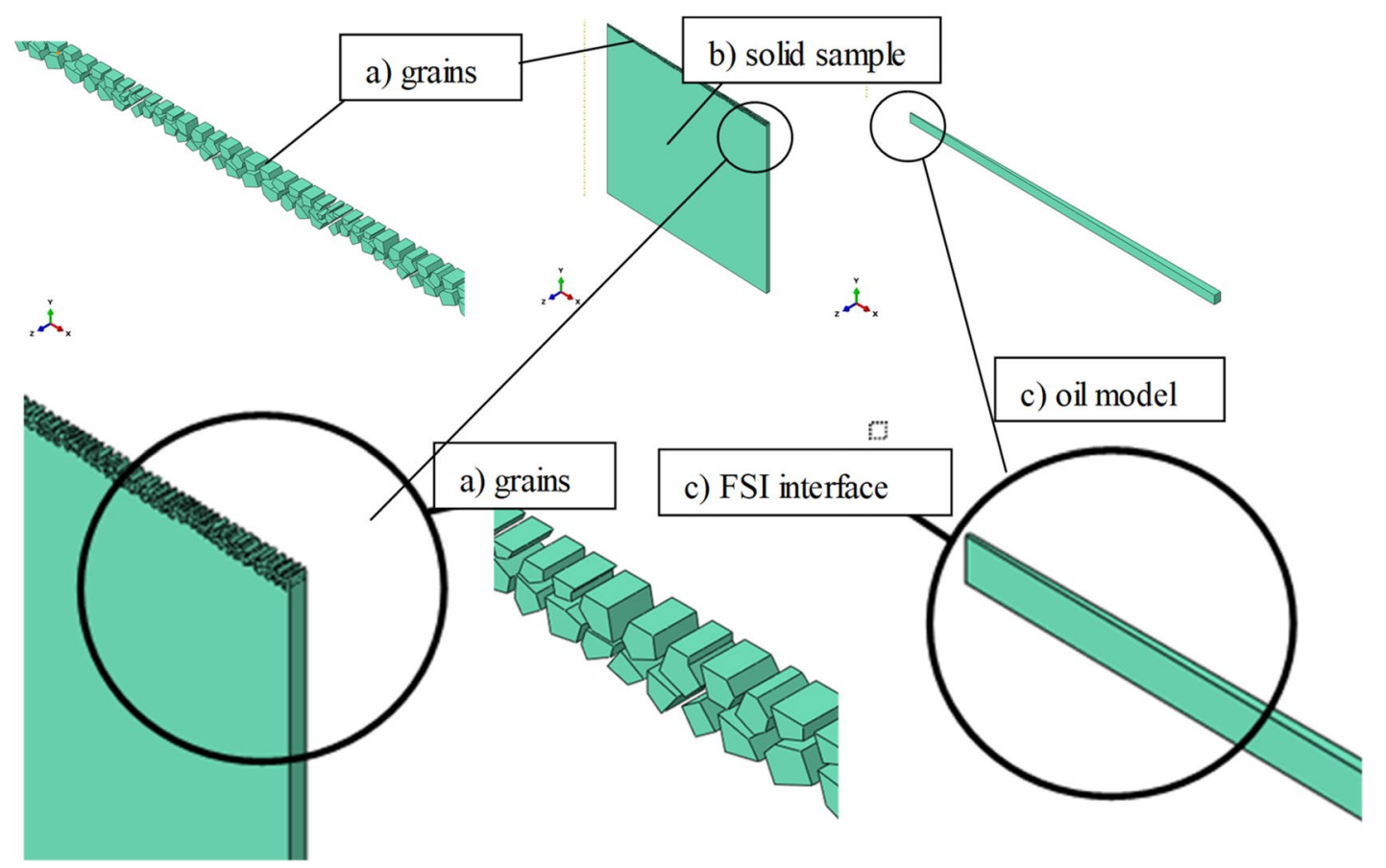

Fig. 15 The parts of the model: a grains, b steel sample model (solid) with a grain layer $\mathbf{c}$ oil model (liquid) 
Fig. 16 Complete FSI model with a finite element mesh

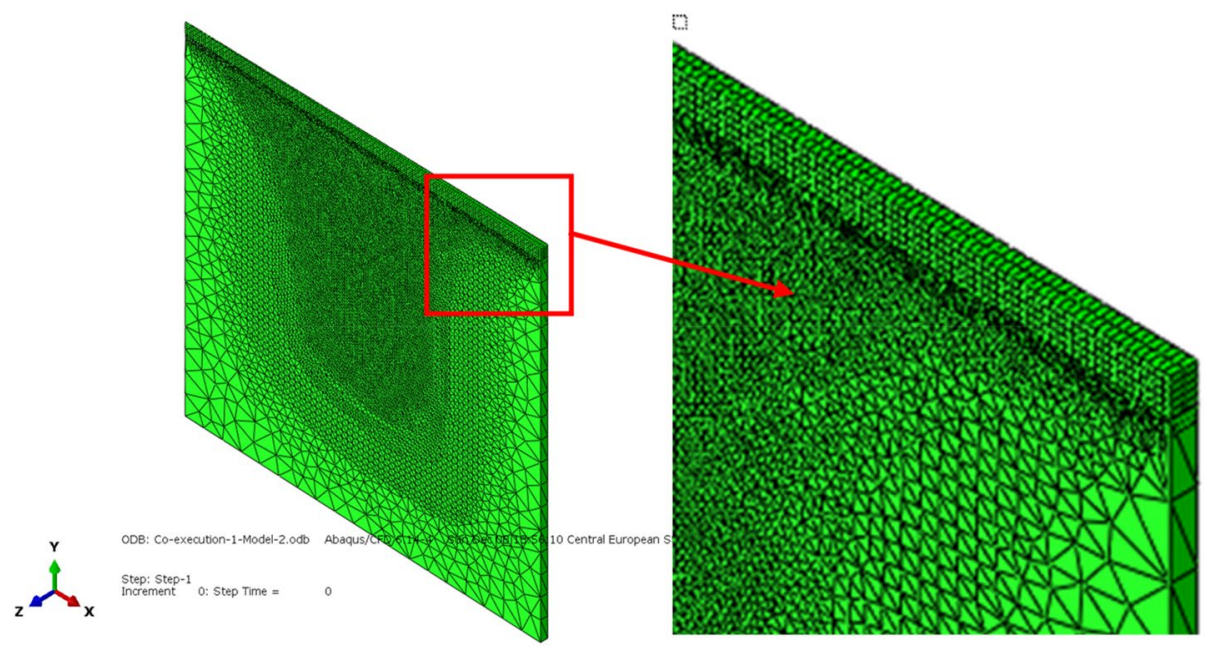

Fig. 17 a-d Deformed grains for normal load: a $0 \mathrm{MPa}$, b $300 \mathrm{MPa}, \mathbf{c} 450 \mathrm{MPa}$, d $600 \mathrm{MPa}$

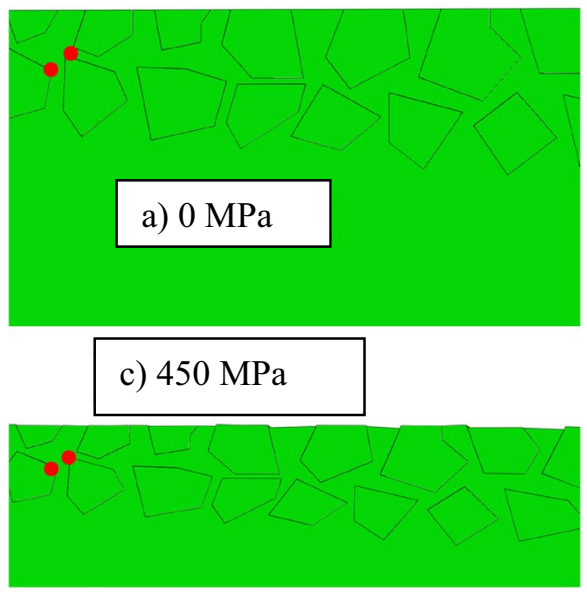

b) $300 \mathrm{MPa}$

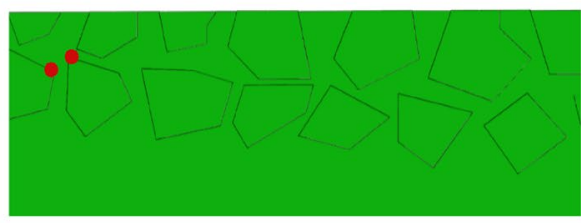

d) $600 \mathrm{MPa}$

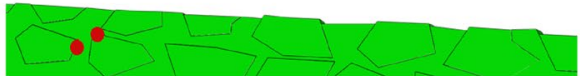

fragments of samples before and after loading. On the right, the enlarged parts of the samples with the surface and the surface layer with the grains are shown. Before loading, the smooth surface turned to rough when the contact force was applied.

Comparison of the results of deformation-induced roughening of surfaces obtained in the experiment and in the numerical simulation is shown in Fig. 20 (as a function of load) and 21 (as a function of thickness reduction). As you can see, not only trends but also the roughness values of the newly created surface structure are similar. In the case of dependence on the load (Fig. 20), the first phase of the loading up to the yield point (300 MPa) causes no change in roughness. In the second phase, the results of deformed-induced roughness for the experiment and numerical simulation are very similar. The presented model allowed calculation of roughness changes in these two phases, the third one-roughness degradation is not counted (Fig. 21).

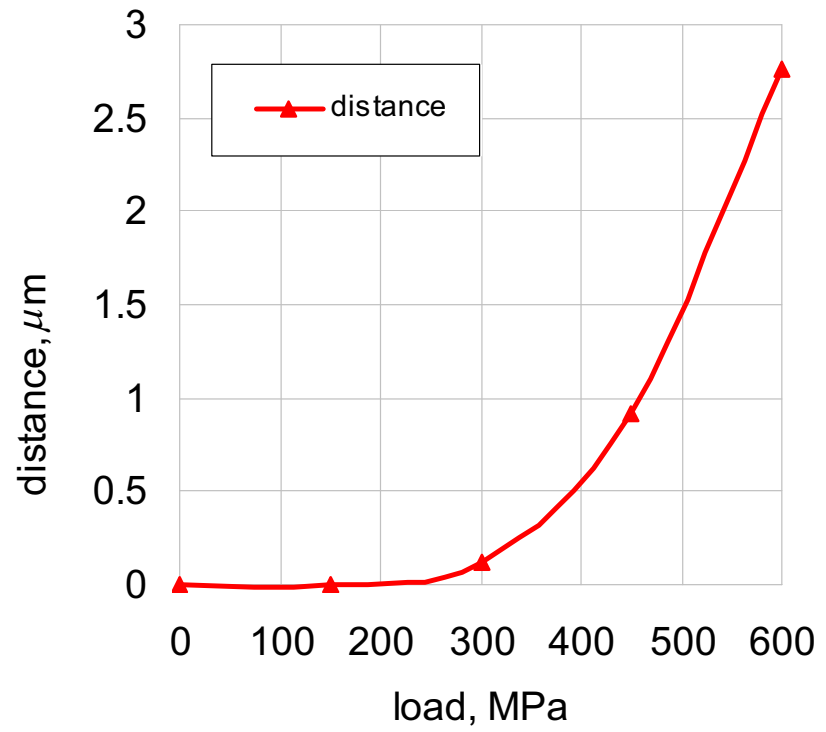

Fig. 18 Change of the relative distances between grains as a function of normal contact loading 


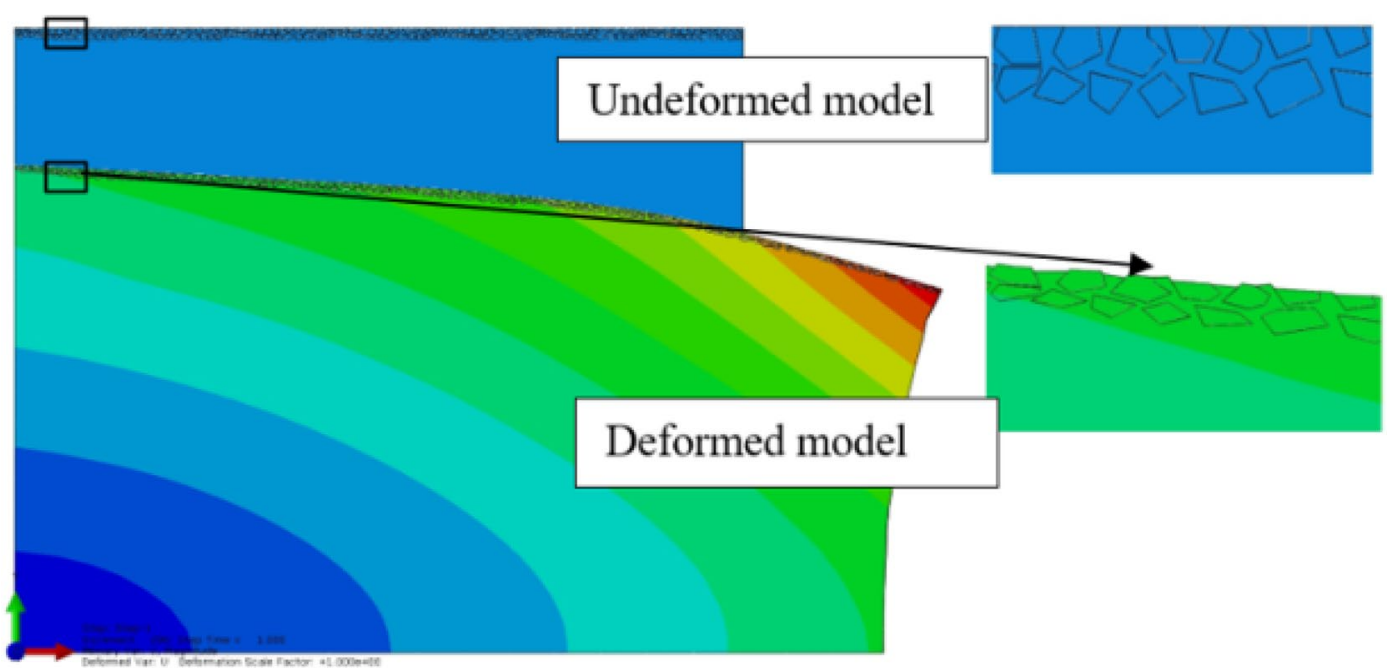

Fig. 19 Initial and final view of the steel sample

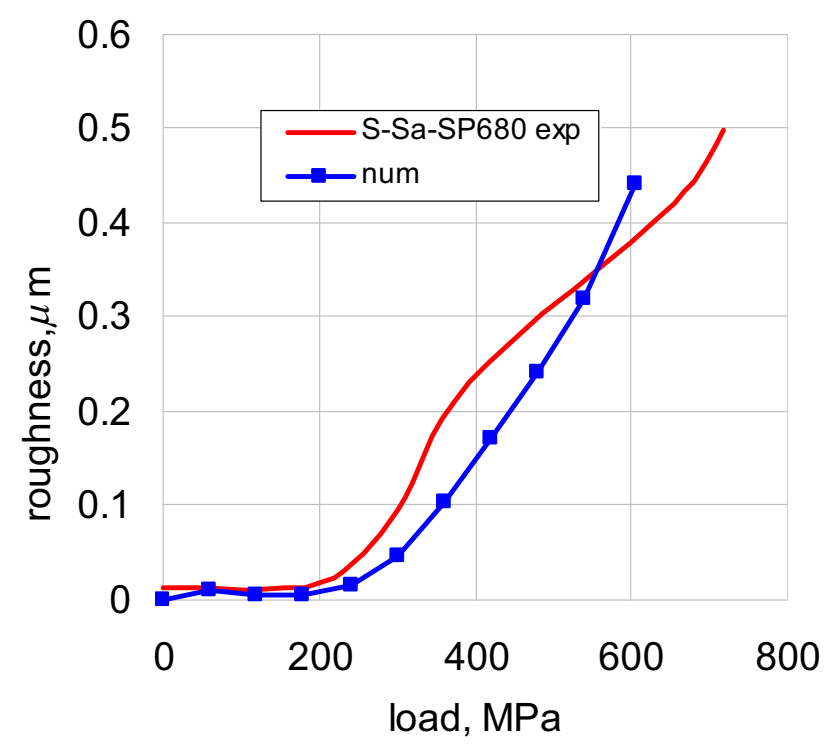

Fig. 20 Comparison on deformation-induced roughness versus normal load between experimental and numerical results for S235 steel and high viscosity oil

\section{Conclusions}

The compression of smooth polished samples in the presence of oil forms a new structure on the surface of samples. The roughness of this structure is dependent on the viscosity of oil: the more viscous the liquid is, the rougher texture is formed. The structure appears beyond the yield point, and is homogeneous and isotropic. Three phases of surface deformation can be clearly seen to change its structure: 1 -below the yield point-no change in surface roughness, 2 - the new structure of surface resulting from

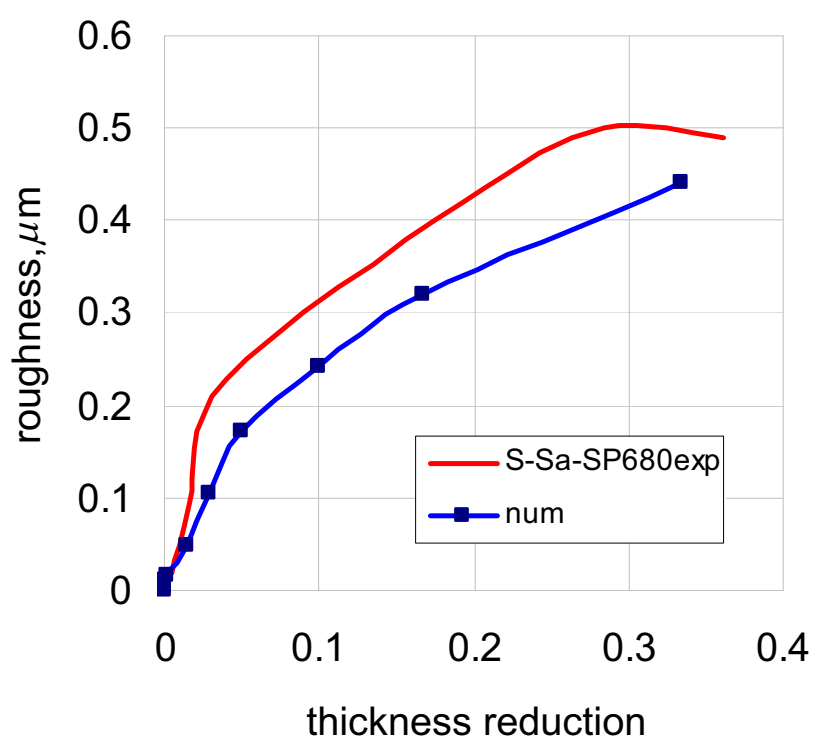

Fig. 21 Comparison on deformation-induced roughness versus thickness reduction between experimental and numerical results for S235 steel and high viscosity oil

rotation and deformation of surface grains is generated up to a critical point, 3-beyond certain critical point the roughness is reduced, because the surface is crushed by a counter sample.

There is a critical point below which compression causes further increase in roughness and above which the asperities get crushed. Critical points are between 20 and $30 \%$ of the total deformation of the sample and depend on the loading history and sample material. This point is different for various materials and is mainly associated with the number of generated asperities. The tests involving step increments 
of loads allow us to estimate that the average roughness $S_{\text {a }}$ above which asperities will be crushed, and below which they will still be formed. For austenitic steels and oil SP680 it is $0.24 \mu \mathrm{m}$, while for $\mathrm{S} 235$ steel the estimated value is $0.4 \mu \mathrm{m}$.

With large deformations (above 0.3), the difference between roughness for different oils disappears, especially for horizontal parameter $P_{\mathrm{sm}}$. It is related to the dominance of flattening of previously built asperities by a counter sample. Further deformation causes the structure to stabilize at $30 \mu \mathrm{m}$ for H18N9 austenitic steel and $45 \mu \mathrm{m}$ for S235 carbon steel.

The problem of formulating roughening by contact compression in the presence of oil has been clarified using FE numerical calculations. The changes in the structure of the smooth surface are caused, as in the case of tension, by the rotation and deformation of surface grains.

In the research carried out and presented in this work, changes in the structure of the smooth surface resulting from compression in the presence of oil are caused, as in the case of tension, by the rotation and deformation of surface grains. This has been shown in the numerical model. In addition, during compression with oil, the viscosity of the fluid affects the surface structure formed.

\section{Compliance with Ethical Standards}

Conflict of interest Authors declare that we do not have any commercial or associative interest that represents a conflict of interest in connection with the work submitted.

Ethical Approval Authors state that the research was conducted according to ethical standards.

Open Access This article is licensed under a Creative Commons Attribution 4.0 International License, which permits use, sharing, adaptation, distribution and reproduction in any medium or format, as long as you give appropriate credit to the original author(s) and the source, provide a link to the Creative Commons licence, and indicate if changes were made. The images or other third party material in this article are included in the article's Creative Commons licence, unless indicated otherwise in a credit line to the material. If material is not included in the article's Creative Commons licence and your intended use is not permitted by statutory regulation or exceeds the permitted use, you will need to obtain permission directly from the copyright holder. To view a copy of this licence, visit http://creativecommons.org/licenses/by/4.0/.

\section{References}

1. Osakada, K., Oyane, M.: On the roughening phenomenon of free surface in deformation process. Trans. Jpn. Soc. Mech. Eng. 36(286), 1017-1022, 0375-9466 (1971)
2. Dai, Y.Z., Chiang, F.P.: On the mechanism of plastic deformation induced surface roughness. J. Eng. Mater. Technol. 114(4), 432-438 (1992)

3. Wilson, D.V., Roberts, W.T., Rodrigues, P.M.B.: Effect of grain anisotropy on limit strains in biaxial stretching: part I: influence of sheet thickness and grain size in weakly textured sheets. Metall. Trans. A 12, 1595-1602 (1981)

4. Mahmudi, R., Mehdizadeh, M.: Surface roughening during uniaxial and equi-biaxial stretching of 70-30 brass sheets. J. Mater. Proc. Technol. 80-81, 707-712 (1998)

5. Wouters, O., Vellinga, W.P., Van Tijum de Hosson, R.J.T.M.: On the evolution of surface roughness during deformation of polycrystalline aluminum alloys. Acta Mater. 53, 4043-4050 (2005)

6. Romanova, V., Balokhonov, R., Zinovieva, O.: A micromechani$\mathrm{cal}$ analysis of deformation-induced surface roughening in surface-modified polycrystalline materials. Meccanica 51, 359-370 (2016)

7. Wang, X., Abe, T., Tada, N., Shimizu, I.: Microscopic surface change of polycrystalline aluminum during tensile plastic deformation. Mem. Faculty Eng. Okayama Univ. 39, 7-15 (2005)

8. Song, H.L., Abe, T., Shimizu, I., Tada, N., Torii, T.: Observation of microscopic plastic deformation of polycrystalline aluminum during uniaxial tension by confocal laser-scanning microscope. Key Eng. Mater. 274-276, 337-342 (2004)

9. Zhou, X.H., Su, X.: Surface roughening during deformation of polycrystalline aluminum and titanium alloys. J. Eng. Mater. Technol. ASME 132, 041001-1-41006 (2010)

10. Shia, Y., Wua, P.D., Lloydb, D.J., Embury, D.: Numerical study of surface roughening in blow-formed aluminum bottle with crystal plasticity. Mater. Sci. Eng. A 638, 97-105 (2015)

11. Cai, Y., Wang, X., Yuan, S.: Analysis of surface roughening behavior of 6063 aluminum alloy by tensile testing of a trapezoidal uniaxial specimen. Mater. Sci. Eng. A 672, 184-193 (2016)

12. Emelianova, E., Romanova, V., Zinovieva, O., Balokhonova, R.: The effects of surface-layer grain size and texture on deformationinduced surface roughening in polycrystalline titanium hardened by ultrasonic impact treatment. Mater. Sci. Eng. A 793, 139896 (2020)

13. Romanova, V., Balokhonova, R., Emelianova, E., Pisarev, M., Dymnic, E.: Numerical study of the texture effect on deformationinduced surface roughening in titanium polycrystals. Eng. Fail. Anal. 110, 104437 (2020)

14. Romanova, V., Balokhonova, R., Panina, A., Kazachenoka, M., Kozelskaya, A.: Micro- and mesomechanical aspects of deformation-induced surface roughening in polycrystalline titanium. Mater. Sci. Eng. A 697, 248-258 (2017)

15. Romanova, V., Balokhonova, R., Zinovieva, O., Shakhidjanov, V.: Numerical study of the surface hardening effect on the deformation-induced roughening in titanium polycrystals. Comput. Mater. Sci. 116, 96-102 (2016)

16. Kucharski, S., Starzynski, G.: Prediction of surface roughness in metal forming with liquid lubricant. Tribol Int 43, 29-39 (2010)

17. Kucharski, S., Starzynski, G.: Study of contact of rough surfaces: modeling and experiment. Wear 311, 167-179 (2014)

Publisher's Note Springer Nature remains neutral with regard to jurisdictional claims in published maps and institutional affiliations. 